\title{
Curandeirismo e o campo da saúde no Brasil
}

Rodolfo Franco Puttini ${ }^{1}$

PUTTINI, R.F. Faith healing and the field of healthcare in Brazil. Interface - Comunic., Saúde, Educ., v.12, n.24, p.87-106, jan./mar. 2008.

The general aim of the present paper was to contribute towards the discussion on the field of healthcare. Specifically, the aim was to contribute towards reflections on the hegemonic power of medicine and its relationships with practices of faith healing. Taking into account the field and habitus of Pierre Bourdieu's theory, faith healing is discussed based on a review of the concept of trance in the intellectual field as an object of scientific habitus formed between medical practice and religious practice. Finally, by means of contemporary themes shared by social sciences and public health, it is shown how faith healing - a negative term within the field of medicine - is transformed into a positive term within the field of public health.

Key words: Religion and medicine. Healthcare. Spirituality. Spiritual therapies.
O objetivo geral do presente artigo é colaborar para a discussão sobre o campo da saúde. Especificamente, pretende-se contribuir para a reflexão do poder médico hegemônico e suas relações com as práticas relacionadas às curandeirices. Considerando a teoria do campo e do habitus de Pierre Bourdieu, discute-se sobre o curandeirismo com base em uma revisão do conceito de transe no campo intelectual como objeto do habitus científico formado entre a prática médica e a prática religiosa. Finalmente, por meio de temas contemporâneos compartilhados pelas Ciências Sociais e pela Saúde Coletiva, indica-se como o curandeirismo - aspecto negativo para o campo médico - transforma-se em aspecto positivo no campo da Saúde Coletiva.

Palavras-chave: Religião e medicina. Saúde. Espiritualidade. Terapias espirituais.

odolfo Franco Puttini 


\section{Curandeirismo: um perigo à saúde pública?}

Nota-se claramente o progresso social na sentença geral da Organização Mundial de Saúde $\mathrm{OMS}^{2}$, que, desde 1946, volta-se, no contexto mundial, para a atenção à saúde das populações. A continuidade dessa diretriz internacional foi fortalecida na Conferência Internacional sobre Cuidados Primários para a Saúde, de onde se propagou a meta "saúde para todos no ano 2000" (WHO/ UNICEF, 1978, p.1), não sem críticas (Cueto, 2004; Rivero, 2003; Segre \& Ferraz, 1997). Novos avanços da prática da saúde pública foram apresentados na Carta de Ottawa (WHO, 1984), que propõe, em continuidade ao movimento sanitário, uma política internacional da promoção da saúde (Buss, 2003). No Brasil, o Sistema Único de Saúde (SUS), implantado no final da década de 1980, decorrente daquela proposição mundial junto ao movimento sanitário brasileiro, influiu na promulgação de diretrizes e princípios para a prática profissional no campo da saúde. No campo intelectual, inquietações epistemológicas recentes pensam o âmbito paradigmático da saúde pelos diversos sentidos do conceito (Coelho \& Almeida Filho, 2002; Almeida Filho, 2001), denotando a importância dos caracteres positivos da definição (Czeresnia, 2005), fundamentais para a formulação de uma teoria geral para o campo da saúde (Samaja, 1997).

Este artigo pretende contribuir para essa discussão geral sobre o campo da saúde no contexto da Saúde Coletiva, partindo de ponderações sobre o habitus científico formado entre a prática médica e a prática religiosa. Especificamente, tendo por referencial a teoria do campo e do habitus de Pierre Bourdieu, discutirei a hegemonia do poder médico pelas relações com as práticas curandeiras por meio do exame do percurso do conceito de transe no campo intelectual brasileiro.

Utilizo a referência teórica de Bourdieu, que assim define habitus:
2 " [...] saúde é o estado de bem-estar físico, psicológico e social, e não mera ausência de doenças $[\ldots]^{\prime \prime}$. (WHO, 1948, p.1)

O autor associa o sentido de habitus à noção de campo, assim definida:

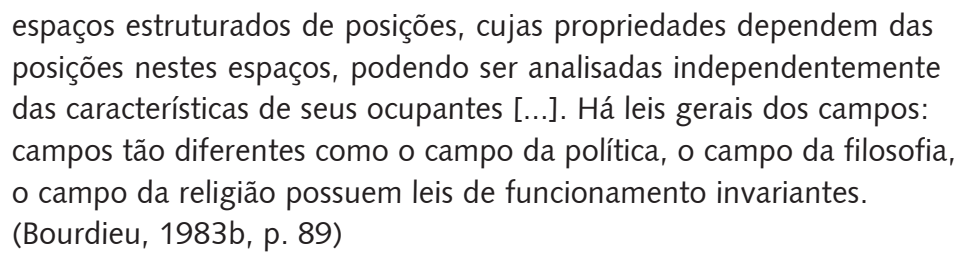
posições nestes espaços, podendo ser analisadas independentemente das características de seus ocupantes [...]. Há leis gerais dos campos: campos tão diferentes como o campo da política, o campo da filosofia, o campo da religião possuem leis de funcionamento invariantes. (Bourdieu, 1983b, p. 89)

No interior da teoria geral dos campos, Bourdieu explicita que campo é o local de socialização do habitus, cujo poder simbólico impõe significações que demandam legitimidades. Os símbolos afirmam-se, então, na prática como instrumentos de integração social, possibilitando a reprodução de uma ordem estabelecida sem conflitos. Especialmente para o campo científico, o autor orienta de que se trata de um campo social composto por relações de forças, 
${ }^{3}$ É consensual apresentar as entidades filantropias como empresas benemerentes, prestadoras de serviços na área da saúde e coadjuvantes das políticas públicas de saúde. Para a crítica à filantropia, confrontar: Portela et al., 2004; Mestringer, 2001; Giumbelli, 1995; Landim, 1993; Guedes, Barata, Corrêa, 1988.

${ }^{4}$ A opinião de risco do curandeirismo parece associada à redação dos

textos legais: "Parece que o legislador de 1890 se inspirou nas Ordenações para elaborar o artigo 157: 'Praticar o espiritismo, a magia e seus sortilégios, usar de talismã e cartomancias, para despertar sentimentos de ódio ou amor. inculcar curas de moléstias curáveis ou incuráveis, enfim, para fascinar e subjugar a credulidade pública' (Peixoto, 1980, p.113). Já no código modificado pelo decreto-lei $\mathrm{n}^{\circ}$ 2.848, de 7 de dezembro de 1940, lêem-se os seguintes artigos penais correlacionados com a prática médica oficial: Art. 284 -

Curandeirismo: Exercer o curandeirismo: I prescrevendo, ministrando ou aplicando,

habitualmente, qualquer substância; II - usando gestos, palavras ou qualquer outro meio; IIIfazendo diagnósticos: Pena: detenção. lutas e estratégias que não estão estruturadas pela ordem do mundo empírico, mas pela práxis. A atividade científica "engendra-se na relação entre disposições reguladas de um habitus científico que é, em parte, produto da incorporação da necessidade imanente do campo científico e das limitações estruturais exercidas por esse campo em um momento dado do tempo" (Bourdieu, 1996, p.88).

As preocupações iniciais do presente trabalho surgiram de indagações específicas a respeito de práticas espirituais professadas no interior de determinadas instituições de saúde, mais precisamente em hospitais psiquiátricos administrados por empresas filantrópicas do espiritismo kardecista ${ }^{3}$. Constatei um resultado importante da investigação antropológica: o consenso entre os agentes sobre o espaço de cura espiritual, identificado no interior do hospital como atividade terapêutica complementar à prática médica. Notamos, ainda, a postura de médicos e profissionais da saúde adeptos da religião que, posteriormente à construção do espaço terapêutico, mantinham-se convictos em construir as bases da "medicina espírita", crença maior do espiritismo científico.

Novos questionamentos, no entanto, reorientam-se pela seguinte pergunta: em que circunstâncias se podem considerar complementares práticas espirituais de cura e práticas médicas? Na Saúde Coletiva, tornou-se um marco histórico o reconhecimento da homeopatia e da acupuntura, hoje especialidades médicas, mas outrora consideradas práticas terapêuticas ilícitas. Ao ganharem aceitação da comunidade científica, a homeopatia e acupuntura deslocaram-se do limiar jurídico para outra instância do saber-poder, em cujo embate dirige-se atualmente para o progresso científico dos respectivos sistemas médicos (Rosenbaum, 1999; Rebollo, 1993). Entretanto, a discussão sobre complementaridade de práticas terapêuticas não-médicas (Barros, 2000), abordada também sob o ângulo das racionalidades médicas (Luz, 1993) gerou, recentemente, a polêmica epistemológica centrada na constatação de que

mais e mais práticas terapêuticas 'complementares' foram se incorporando à rede pública de serviços durante a década de 90 , além das já tradicionais previstas em lei desde o advento do Sistema Único de Saúde (SUS) ao final dos anos 80: homeopatia, acupuntura e fitoterapia. (Luz, 2005a, p.39)

Diante dos fatos, questiono mais aprofundadamente sobre tais paradoxos: em que medida questões espirituais demarcam a cientificidade das racionalidades médicas no campo da saúde? Talvez, uma solução seja distinguir conceitualmente novas terapêuticas das práticas de saúde já consagradas (Luz, 2005b) ou, ainda, pensar a espiritualidade na discussão do cuidado (Ayres, 2005). No entanto, tomo por base que as práticas espirituais põem à vista aspectos negativos e positivos do curandeirismo.

Pretendo demonstrar que o curandeirismo nas ciências sociais, termo considerado um perigo à saúde pública no campo jurídico (Peixoto, 1980)4, transita como produto simbólico no campo da saúde. Para tanto, faço um exame da controvérsia decorrente do conceito de transe no campo intelectual, revisão teórico-conceitual que garantirá, no final do texto, refletir sobre as atuais relações entre prática médica e práticas espirituais. 


\section{Estado de transe e curandeirismo: doença mental e/ou produto da cultura}

Os interesses históricos pelo pensamento médico no Brasil convergem atualmente para o resgate da história social da medicina. Rodrigues (1862-1906) tem sido solicitado como referência intelectual para diferentes temas das ciências sociais. Por exemplo, buscam-se, na sua biografia: as origens da antropologia brasileira (Correa, 2000), as elucidações na discussão racial (Oda, 2003; Schwarcz, 1993), os esclarecimentos conceituais da "medicalização da sociedade" (Antunes, 1999) ou do movimento eugênico no Brasil (Stepan, 2005), as demonstrações dos entrecruzamentos entre medicina e direito (Schritzmeyer, 2004), o entendimento da estrutura do campo médico (Maio, 1995) e da estrutura do campo religioso (Giumbelli, 1997a), os elementos da história da psiquiatria no Brasil (Costa, 1989; Machado et al., 1978), enfim, elementos reflexivos para explicitar dilemas mais atuais da democracia racial (Maio \& Santos, 2005; Antunes, 1999).

Para este estudo afirmo que Rodrigues foi o representante mais eminente do pensamento médico que defendeu o estado de transe como moléstia mental. Alcançou notoriedade no âmbito internacional, dada a influência do posto de professor e pesquisador que ocupou na Faculdade de Medicina da Bahia até o último quartel do século XIX, cujas potencialidades Ihe foram proporcionadas para desenvolver, no ambiente científico, teorias médicas baseadas nas etiologias das doenças mentais de concepção organicista. Numa época de desenvolvimento dos valores evolucionistas na Europa, sobretudo pela idéia da degenerescência com base centrada no reducionismo biológico aplicado à psiquiatria, com essas preocupações, em 1890, Rodrigues publicou seu segundo livro em Paris, $L$ 'animisme fétichiste dês nègres de Bahia, traduzido posteriormente pelo médico e antropólogo brasileiro Arthur Ramos (Rodrigues, 1935). Rodrigues expõe detalhadamente a teoria sobre o estado de transe, associando-a à teoria da degenerescência. Partindo da definição do estado de transe, o autor abordou o negro africano dos terreiros nagôs da Bahia como protótipo da incapacidade mental por não conseguir abstrair o modelo religioso monoteísta do ocidente, um sinal de superioridade religiosa da civilização ocidental. Foi dessa forma que Rodrigues justificou a possibilidade de pensar a teoria do transe por meio da transmissão de caracteres patológicos nas raças humanas.

A teoria da evolução social, também defendida pelos parâmetros do modelo médico biológicoevolucionista de Rodrigues, foi reconhecida por parceiros do campo da ciência, doutores da lei (juristas) e médicos (notadamente médicos higienistas da Faculdade de Medicina da Bahia e da Faculdade de Medicina do Rio de Janeiro). O autor, ao identificar a mestiçagem e os cultos mágicoreligiosos com a barbárie, certamente construiu uma contradição lógica para a construção do projeto nacional de civilização (Oda, 2003).

Em estudos recentes, Rodrigues é identificado, pela sua trajetória acadêmica, como cientista que marcou o avanço institucional da profissão médica no Brasil (Maio, 1995). Fundador da disciplina medicina legal, que se tornou uma tradição na clínica médica brasileira de época, Rodrigues influenciou na estruturação do campo da saúde. No entanto, explicita Schritzmeyer (2004), antropóloga que estudou as teorias antropológicas desenvolvidas por Rodrigues, os interesses médicos evidenciaram-se na forma corporativa jurídico-político e contribuíram para a constituição das regras de controle social, promulgadas no Código Penal desde 1890, garantindo, assim, para a corporação médica, a "proteção contra quem quer que os ameace enquanto os únicos peritos do corpo e da cura". Para Schritzmeyer (2004), nesse período, instaura-se uma guerra político-policialjurídica contra os agentes terapêuticos populares e suas respectivas atuações curativas:

"Curandeiros, charlatões e exploradores da credulidade pública propiciaram a união de médicos e juristas diante de um só objetivo: o resguardo da saúde e da credulidade públicas" (p.73). De fato, o argumento jurisprudente para o crime de curandeirismo raciocinava-se pela ótica científica da prática médica aplicada à coletividade, legislação pela qual se pretendia proteger a população das falsas crenças e das falácias profissionais, reprimindo os falsários (Peixoto, 1980). As práticas mágicas de cura seriam, então, perseguidas e punidas na forma da lei, também por meio da ordem de repressão policial (Chalhoub et al., 2003). Interessante notar que o espiritismo kardecista, a umbanda, o candomblé e a homeopatia igualmente eram perseguidos e tipificados por terapêuticas mágico- 


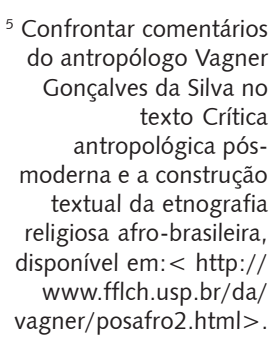

${ }^{6} \mathrm{O}$ trabalho de Ferretti (2001) oferece um panorama crítico sobre a discussão ideológica do sincretismo em relação à ideologia da pureza nagô produzida por Roger Bastide. Para o autor, os conflitos surgem quando aparece o interesse de Bastide em distinguir os cultos de transe baianos pela pureza e sincretismos, perspectiva adotada desde Rodrigues. Essa polêmica foi abordada por Giumbelli (1997a) em referência à

classificação de Roger Bastide das três formas de espiritismo em Le spiritism au Brésil (Bastide, 1967). religiosas, fenômenos mágicos que se expunham ameaçando a ordem social (Giumbelli, 1997b).

Coube a Roger Bastide (1898-1974), intelectual atuante na década de 193040, o primeiro diálogo com o campo médico no contexto de estruturação das ciências sociais brasileiras. Com base nas manifestações religiosas do transe no candomblé baiano - que foram tipificadas por Rodrigues como exemplo de maior grau de doença mental -, Bastide descreveu o fenômeno no contexto religioso e como prática cultural. Contrapôs os tipos de transe místico, psicopatológico e psiquiátrico ao transe nagô do candomblé da Bahia, objeto de maior interesse em seus estudos antropológicos sobre os cultos de possessão (Bastide, 1972, 1960).

Perante o pensamento médico do século XIX, que considerava formas patológicas o comportamento de pessoas em estado de transe no ritual do candomblé baiano, o sociólogo francês, desenvolveu um discurso contrahegemônico a essa referência de doença mental por excelência. A elaboração desse conjunto específico de conhecimento sociológico contra o ideário médico psiquiátrico nascente teve por motivo primeiro esclarecer sobre a possibilidade de outras interpretações do estado de transe, explicitando seus condicionamentos e suas aplicações fora do contexto das diagnoses e terapêuticas médico-psiquiátricas. Seus referenciais teóricos estavam marcados pelas ciências sociais contemporâneas e suas teorias provinham das recentes sociologias da religião de Emile Durkheim, Marcel Mauss, Bronislaw Malinowsky, Max Weber. Pode-se afirmar, nesse contexto, que Bastide foi o primeiro intelectual a ponderar o conceito de estado de transe fora da teoria médica da escola antropológica de Raimundo Rodrigues.

É importante destacar que Bastide optou pela antropologia simbólica francesa, interessada na restituição de mitologias das sociedades tradicionais africanas. Posicionou-se, na ocasião, contra a escola culturalista norteamericana, possibilitando descrever o universo mítico do candomblé baiano enquanto fonte etnográfica primordial para o entendimento cultural do negro africano sobrevivente no Brasil $^{5}$. Embora presumindo o negro africano integrado à religiosidade brasileira, Bastide (1960) não tinha por objetivo discutir o sincretismo religioso. Este será um conceito-chave para Cândido Camargo, que, nos anos de 1960 o associa às religiões mediúnicas. Importava mais a Bastide traçar uma epistemologia voltada a consolidar os estudos sobre a cultura brasileira, tendo por base de trabalho especificar o lugar do transe religioso no candomblé baiano ${ }^{6}$.

No entanto, Ortiz (1978) não poupou críticas a essa sociologia da religião de Bastide e, também, à de Cândido Camargo mais tarde, cujo interesse na temática do sincretismo religioso voltou-se a provar que a umbanda, e não o candomblé, transformava-se na religião mais genuinamente brasileira. Ao retomar o tema do reconhecimento social da umbanda enquanto prática mágica candidata a religião oficial, nota-se a recuperação da discussão ideológica sobre a terapia umbandista: Oritz apresenta o modelo do transe religioso de Bastide como representação final, inversamente modificado numa ideologia atribuída aos intelectuais umbandistas.

embora as novas concepções do transe não sejam ainda do domínio público, é certo, porém, que elas já penetraram a camada de intelectuais umbandistas. Uma curiosa inversão se opera: de forma patológica a possessão passa a ser encarada como meio de vencer a doença mental, como terapia. (Ortiz, 1978, p.30) 


\section{Estado de transe e práticas terapêuticas nas ciências sociais brasileiras}

Pensando as relações conceituais entre curandeirismo e estado de transe também pelo campo intelectual, a sociologia da religião de Ortiz - para quem a umbanda deveria ser considerada a única religião genuinamente nacional porque, para ele, a mais sincrética - mais se aproxima do contexto ideológico formado pela teoria das religiões mediúnicas de Camargo (1961).

Para Camargo, que trabalhou com o conceito de continnum mediúnico, a umbanda ocupava uma posição hierarquicamente inferior às demais religiões mediúnicas brasileiras. No pensamento e projeto intelectual desse autor, o conceito de sincretismo religioso esteve voltado para fundamentar a idéia de continuum, resultando, enfim, na construção das religiões mediúnicas como elemento conceitual importante na constituição do campo religioso no Brasil (Camargo, 1973). Construído na década de 1960, o modelo teórico das religiões mediúnicas implicava o conceito de continuum mediúnico como explicação universalizante com base nas transferências rituais verificadas entre as crenças afro-brasileiras e kardecistas (Camargo, 1961).

Embora o modelo teórico tenha sido criticado por vários autores, observa-se que, na literatura das ciências sociais, Camargo, pela primeira vez, marcou as distinções de modo enfático, destacando os aspectos terapêuticos entre as religiões mediúnicas (Camargo, 1961). Proporcionada pela própria teoria, o sociólogo identificou as diferentes práticas terapêuticas como elementos de integração social no referencial sociológico funcionalista. O destaque era para a função terapêutica da religião, que pertence à função complementar de integração do indivíduo na sociedade. Descreveu detalhadamente o sistema espírita reconhecendo seu público consumidor nas pessoas nervosas que, nos espaços da religião, se adaptavam à sociedade urbana, tendo a oportunidade de desenvolvimento da mediunidade religiosa enquanto forma terapêutica.

Essa constatação não foi resultado de um debate que relacionasse doença mental e estado de transe, como fez Bastide (1972) quando pensou as relações entre manifestações mediúnicas e as doenças mentais na psiquiatria desde os anos de 1930 ${ }^{7}$. Para Camargo, a terapia mediúnica foi interpretada como um elemento sociológico importante para o estudo da crença religiosa, consistente na forma de uma etiologia e terapêutica das doenças e que tinha sua função específica no processo de adesão religiosa do indivíduo na sociedade. Por suas palavras, "a eficácia prática demonstrada pela cura, seu caráter experimental e significado moral, em termos de minoração dos sofrimentos humanos, constitui poderoso elemento de convicção" (Camargo, 1961, p.96).

Preocupado em delimitar o campo religioso, o autor, por conseguinte, tomou cuidado em demonstrar a existência de um mercado das terapias mediúnicas com base na autonomia dessas religiões em relação aos serviços médicopsiquiátricos. Ao espiritismo, em particular, associava duas razões centradas na perspectiva da mudança cultural paulista: a) a existência de uma tradição brasileira de terapêutica sacral; b) a existência de uma inoperância da medicina oficial brasileira. Essas duas razões funcionais das religiões mediúnicas em geral bastariam para dar início a outro ramo na pesquisa sociológica do campo religioso no Brasil ${ }^{8}$, caso as críticas de Ortiz (1978) não alcançassem repercussões intelectuais importantes na comunidade de cientistas sociais brasileiros.

Confrontando a possibilidade da terapia de transe (mediúnico) enquanto prática terapêutica não-oficial, por um lado, Ortiz apontava as limitações

\author{
7 Interessante notar que \\ o médico Bezerra de \\ Menezes, convertido ao \\ espiritismo no início do \\ século $\mathrm{XX}$, propagou \\ uma teoria semelhante \\ que resgatava os \\ aspectos positivos do \\ espiritismo, \\ identificando o \\ desenvolvimento da \\ mediunidade no \\ indivíduo doente, \\ momentaneamente \\ possuído pelos espíritos \\ Essa teoria foi inspirada \\ na experiência que o \\ autor passara com seu \\ próprio filho, durante \\ anos em estado de \\ possessão, curado por \\ meio do \\ desenvolvimento $\mathrm{da}$ \\ mediunidade em um \\ centro espírita no Rio de \\ Janeiro. Confontar \\ Bezerra de Menezes \\ (1987) e David Warren \\ (1984)
}

\footnotetext{
${ }^{8}$ Como se pode verificar na época, por exemplo, em Carlos Brandão, a continuidade da discussão sobre o campo religioso pelas ações católicas, evangélicas e mediúnicas (Brandão, 1980), ou a discussão sobre religião popular (Fernandes, 1984), ou, mais recentemente, sobre a umbanda (Negrão, 1996).
} 
ideológicas do mercado de ofertas terapêuticas desenvolvida por Camargo (1961), contrapondo-se ao processo de formação do Estado brasileiro. Por outro lado, e diversamente, indicava opções de investigação social de estudo sobre o campo religioso no Brasil sob dois outros critérios: propôs estudar as práticas terapêuticas pelos pólos da legitimidade e ilegitimidade social, ausentes, até então, na história das religiões brasileiras. O esforço de Ortiz de se desvincular do funcionalismo de Camargo movia-se em direção à crítica da formação do campo religioso brasileiro. Interessava a Ortiz desenvolver debates aos arredores da autonomia do campo religioso, primeiro configurando a especificidade das medicinas alternativas, que veremos acabada nos trabalhos de Loyola (1984) e Montero (1985). Em seguida, outro veio abria-se para investigar a história da umbanda e do espiritismo, cujos resultados mais expressivos encontram-se nos trabalhos de Maggie (1992) e Giumbelli (1997a).

Montero (1985) e Loyola (1984) mobilizaram forças continuadoras de Camargo, muito embora divergissem de seus resultados e metodologias. Partiram do pensamento do autor pela idéia de continuum para repensar o campo das medicinas alternativas. De fato, Camargo manifestou claramente que Montero continuava suas preocupações teóricas na medida em que ela, uma estudiosa das medicinas alternativas, "foi saber se a terapia religiosa constitui sistema de atendimento terapêutico, dotado de lógica interna capaz de explicitar concepções sistemáticas relativas à etiologia das moléstias e às práticas de seu tratamento" (Camargo apud Montero, 1985, p.10). Nesse trabalho, Montero utilizou o pensamento gramsciano para repensar a condição subalterna das medicinas populares. Realçou as representações populares da doença intrínseca às relações entre dominantes e dominados. Sistematizou a demanda de terapêutica popular e indicou rumos para a pesquisa sobre medicinas alternativas. O trabalho de campo foi feito com os freqüentadores dos centros de umbanda, identificando-os como clientes potenciais do atendimento previdenciário. A autora deduziu o sentido dos conflitos entre as duas medicinas, uma medicina mágica e outra oficial, e concluiu sobre a lógica do discurso religioso que, ao dividir em doença material e doença espiritual, demonstrou que trazia embutida a supremacia do espiritual ${ }^{9}$.

Loyola (1984) já havia realizado contemporaneamente uma investigação ssa linha de pesquisa, iniciada na poca por Laplantine \& Rabeyron (1989), mantém-se atual para a autora (confrontar Araújo, 2000) semelhante e anterior à de Montero, esclarecendo o papel das medicinas populares quando transformadas em alternativas aos serviços oficiais de saúde. Com o material de pesquisa obtido por intermédio de etnografia, inquiriu agentes de cura (religiosos e oficiais) no bairro de Santa Rita, no Rio de Janeiro, e constatou o lugar de encontro de um mercado terapêutico de cura. Várias terapêuticas permaneciam sempre em concorrência com a medicina oficial, embora a autora enfatizasse que a clientela se valia simultaneamente de muitas delas, legitimando-as, assim, diante de suas necessidades de cura. Loyola (1984) comprovou a existência de uma oferta ampla de serviços e agentes de cura, detentores de concepções de doenças e terapêuticas próprias, incluindo católicos, protestantes, umbandistas e adeptos do candomblé no espaço urbano. Identificou a todos como agentes populares de cura, para promover posteriormente sua crítica, ao constatar a concorrência simbólica com a área da prática médica, espaço em que atua de modo hegemônico a medicina oficial.

Montero (1985) refletiu as razões de uma medicina popular quando presumiu forças exógenas à religião umbandista, também identificada pelo pensamento mágico (Montero, 1990), enquanto Loyola (1984), com a metodologia praxiológica de Bourdieu, demonstrou a existência das relações entre agentes religiosos e médicos fora dos espaços sagrados, tradicionalmente 
destinados às religiões em geral (igrejas, templos e centros espíritas). Privilegiando as várias práticas terapêuticas concorrentes entre si e com a medicina oficial no campo terapêutico, Loyola (1984) apontou o médico popular como um dentre outros tipos de agentes, todos denominados por especialista da cura do corpo. A característica principal do médico popular era a de mobilizar, para a clientela, os distintos recursos de cura (alopáticos ou não) disponíveis no mercado, e que atuavam, muitos deles, em um sistema de troca de bens simbólicos.

\section{Imagens do curandeirismo e ideologia das religiões mediúnicas}

Até o momento segui a hipótese de que o conceito de curandeirismo exerceu de modo simbólico influência nas ciências sociais brasileiras, uma vez que estavam adequadas as condições para formação de um pensamento crítico em oposição às práticas terapêuticas não-convencionais provenientes do campo religioso. Assim, uma nova problemática metodológica resultou em uma mudança intelectual nas ciências sociais por um grupo de pesquisadores, especialmente antropólogos que, na década de 1980, usaram os estudos de caso para romper com os pressupostos generalizantes das abordagens sociológicas anteriores.

Assim se justificou o trabalho de Velho (1975), que impulsionou criticamente a retomada do tema sincretismo religioso. E, posteriormente, o de Dantas (1982) que, com a mesma justificativa, avançou a crítica à ideologia dos estudos afro-brasileiros, "mostrou que a intelectualidade brasileira que estudou os cultos no candomblé fundou as religiões afro-brasileiras, no sentido de que foi cooptada por um grupo religioso - os nagôs autênticos da Bahia, depositários da africanidade" (Maggie, 1989, p.79). Vale a pena lembrar que Maggie (1986) foi a primeira antropóloga a tomar como unidade de análise um terreiro de umbanda no Rio de Janeiro pressupondo, para estudo antropológico, a descrição de apenas uma instituição religiosa. Sugeriu, enfim, a modificação da noção de comunidade, utilizada na literatura acadêmica sobre as religiões afro-brasileiras desde Rodrigues a Bastide, agora interpretadas por religiões populares ainda com traços primários perdidos no meio urbano. Essa constatação bastou à autora para demonstrar a inconsistência das sociologias desde Bastide até Camargo, dado que as explicações eram mais devidas à ideologia do grupo de intelectuais e não enfatizavam os aspectos conflituosos e subjacentes aos agentes sociais pertencentes aos grupos estudados.

Numa perspectiva semelhante a de Maggie, Seiblitz (1979), motivada pelo estudo específico de um centro espírita no Rio de Janeiro, mencionou que

\footnotetext{
dada a grande penetração que a operação fluídica - prática terapêutica levada a efeito em alguns centros espíritas - tem entre diferentes camadas sociais, encontrando acolhida mesmo por parte dos agentes oficiais de saúde, os médicos, que nos pareciam os últimos, por sua formação profissional, a adotar tal solução. (p.17)
}

Do mesmo modo e antes de Montero (1985), Seiblitz (1979) utilizou-se da metodologia etnográfica pela perspectiva de Gramsci e Bourdieu, orientadores teóricos, para pensar a dimensão ideológica de um ritual (operação fluídica) que envolvia profissionais de saúde adeptos da religião mediúnica.

Por outro lado, a circularidade temática sobre o sincretismo religioso levou Cavalcanti (1983) a propor um estudo endógeno do espiritismo de Kardec. Demonstrou a particularidade do sistema ritual espírita estruturado em três pólos categóricos: estudo, caridade e mediunidade. Esse conjunto categórico define o espiritismo enquanto uma religião sobre as demais religiões mediúnicas. Realça a categoria mediunidade sobre as demais, por duas razões: a) ela é central para se entender o ritual, quando é tomada no sentido de comunicação com os espíritos; b) ela é fundamental, quando no sentido da experiência do transe (recepção do espírito), constitui-se a experiência central dos adeptos da religião. Para a autora, no espiritismo, a mediunidade é o ponto alto da cosmologia religiosa. Essa postura lhe permitiu trazer ao debate uma reinterpretação dos conceitos de transe e possessão que, 
desde Bastide, nunca foram articulados com os teóricos da antropologia. Enquanto Velho (1975) e Dantas (1988) colocaram o kardecismo em segundo plano nas análises sobre a possessão, Cavalcanti (1983), diferentemente dos trabalhos de Seiblitz (1979), Neves (1984) e Neves \& Seiblitz (1984), trouxe para o debate ideológico as características do espiritismo enquanto sistema religioso entre as demais religiões mediúnicas.

Hess (1991) aproximou-se da crítica ideológica ao espiritismo, estudando casos de cientistas brasileiros adeptos da religião sem adentrar nas questões ideológicas no campo intelectual das ciências sociais brasileiras. Todavia, Concone (1983), ao privilegiar os méritos do sincretismo religioso na umbanda, em detrimento das questões ritualísticas, concluiu de outro modo, que se perdia na análise ideológica da produção sociológica sobre o transe, propondo alargar o debate por meio do termo transe de possessão, cuja abrangência do objeto ampliaria o sentido incluindo as religiões tradicionais.

O avanço do debate das ideologias das religiões mediúnicas pode-se verificar com Maggie (1992), que ampliou as considerações cosmológicas, utilizando processos judiciais entre 1890 e 1945 no Rio de Janeiro. Estudou os processos acusados de transgredirem os três artigos penais relacionados a práticas mágicas (curandeirismo, prática ilegal de medicina e charlatanismo). Maggie (1992) colaborou substancialmente para resgatar as relações simbólicas estruturadas entre curandeiros, benzedores, benzedeiras, espíritas, médiuns de todas as espécies e, de outro lado, juizes, promotores, advogados e policiais. O que se pode notar é que a autora defendeu hipóteses de que sempre esteve presente, na história das religiões mediúnicas, o discurso de que o Estado perseguiu e reprimiu macumbeiros, espíritas e umbandistas e seus participantes. Porém, tal justificativa acompanha certo consenso ideológico - quer entre estudiosos (por exemplo, entre Rodrigues, Ramos e Bastide), quer entre mães e pais-de-santo - relativamente à idéia de que a crença sempre foi vencedora. Nesse contexto dos estudos acadêmicos, o sincretismo religioso sempre foi utilizado como resultado dessa repressão: escravos escondem divindades africanas sob a máscara de santos católicos. No referencial do campo religioso, o que vemos é uma disputa intelectual entre as categorias magia e religião, que serviram de base para Maggie (1992) debater as diferenças entre práticas lícitas e ilícitas. A autora demonstrou que os mecanismos reguladores criados pelo Estado a partir da República não extirparam as crenças nos feitiços, mas ao contrário, foram fundamentais para a sua constituição.

Enfim, uma fórmula resultou de seu estudo de caso: para a definição dos feiticeiros no Rio de Janeiro (que a autora aprofundou detalhadamente da etnografia em uma instituição mediúnica), constatou que a feitiçaria é uma categoria que opera logicamente no estabelecimento de relações e hierarquias entre coisas e pessoas, cujos critérios de bem e mal estruturam um status que discrimina uma relação de poder, demonstrando que as religiões mediúnicas são consideradas cultos oficiais, percebidos como práticas de magia benéfica (rituais de invocação dos espíritos), enquanto as feitiçarias e os feiticeiros, que praticam atos criminosos, rituais de magia negra, são os representantes do mal.

Giumbelli (1997a) investiu na crítica ideológica do campo religioso brasileiro pelo estudo histórico do espiritismo. Utilizou-se, também, de processos judiciais para repensar os caminhos de legitimidade da religião, partindo da análise de categorias construídas por atores sociais - espíritas, religiosos, médicos, delegados, juizes, promotores e advogados. Seguiu orientações intelectuais da antropologia, partindo da discussão de Fry (Fry apud Giumbelli, 1997a), ao comentar sobre as investigações de Dantas (1988) a respeito da construção da idéia de pureza nagô nas religiões afrobrasileiras. Segundo Fry (1988), a contribuição de Dantas teve por objetivo relativizar a tese da repressão no candomblé sem substantivar a pureza da religião. Mostrou a configuração das religiões afro-brasileiras por uma série de alianças e conflitos que se entrecruzavam entre senhores, escravos, políticos, psiquiatras, policiais, homens poderosos de negócios, pais e mães-de-santo, padres e antropólogos - e não seguindo as duas grandes interpretações históricas da formação das religiões afro-brasileiras (Fry, 1988).

Investigando as imagens no espiritismo, Lewgoy (2000), em trabalho de doutorado, contribuiu para os estudos do campo religioso demonstrando, nessa linha de pensamento, importantes relações 
entre espiritismo kardecista e a cultura letrada. Por meio do transe mediúnico, levou em conta características peculiares das práticas de cultura letrada enquanto culturais, demonstrando que o espiritismo kardecista estabeleceu-se em um sistema de referências eruditas, distinguindo a religião espírita (ciência e religião) das demais religiões mediúnicas.

Stoll (1999), delineando-se na mesma linha de pensamento de Lewgoy, posicionou as práticas do espiritismo para fora dos espaços sagrados da religião. Argumentando sobre as dissidências entre espíritas no Brasil, divididos entre evangélicos e científicos, defendeu a tese de diferentes interpretações da cultura letrada mediúnica francesa e brasileira identificando, assim, tensões entre escrita mediúnica católica (Chico Xavier) e escrita da cultura da nova era (Luiz Gasparetto). Gasparetto, na década de 1980, ao questionar a prática da mediunidade como forma de exercício de doação, de renúncia e de caridade, própria do modelo de Chico Xavier, desenvolveu um programa "[...] nos espaços que integram o circuito neo-esotérico: a promoção de cursos, palestras, workshops que tematizam questões relativas ao domínio da espiritualidade, da saúde e problemas que envolvem as relações na vida cotidiana" (Stoll, 2002, p.243-4) .

Desse modo, é coerente o seguinte questionamento da autora: o espiritismo aparece como programa religioso ou programa de auto-ajuda? Partindo desse ponto de vista, Stoll (2002) possibilita repensar as demarcações do campo religioso colocando a literatura psicográfica espírita nas fronteiras com o campo literário. O que se pode notar é que as críticas especialmente dirigidas à ideologia espírita (Lewgoy, 2000; Giumbelli, 1997a; Hess, 1989; Cavalcanti, 1983), ao atingir o limiar do campo literário (Stoll, 2002) revelou elementos simbólicos para a análise da autonomia do sistema religioso mediúnico. Assim, Maggie (1992), Velho (1975), Dantas (1982) e Seiblitz (1979) identificaram no conceito religiões mediúnicas o problema central, inerente às ideologias presentes no próprio grupo de pesquisadores: seja para designar a ideologia das religiões afro-brasileiras (Concone, 1983), das próprias religiões mediúnicas (Cavalcanti, 1983) ou das religiões de transe (Rizzi, 1995). Parece plausível perguntar: em que condições podem-se considerar coincidentes os conceitos de auto-ajuda - proveniente do campo religioso (como Stoll denota em relação ao espiritismo) - e de autocuidado - oriundo do campo da saúde? Talvez a resposta da Saúde Coletiva direcione para a compreensão das distinções múltiplas da categoria empowerment, uma aposta para explicar a tendência de manejar recursos de atores informais na comunidade, sujeitos coletivos importantes como "família, comunidades de vizinhos, voluntariado, grupos de auto-ajuda, organizações não-governamentais que, de diferentes formas e com diferentes níveis de envolvimento, desenvolvem funções assistenciais e de cuidado" (Serapioni, 2005, p.244).

No entanto, ao procurar, neste tópico, explorar intelectualmente as imagens do curandeirismo no campo religioso atrelado às críticas ideológicas das ciências sociais ao modelo teórico das religiões mediúnicas de Camargo (1961), pretendi mostrar como o curandeirismo importa ao campo simbólico da saúde. Em trabalho anterior (Puttini, 1989), na perspectiva metodológica de Foucault, analisei os discursos médicos em processos judiciais do crime de curandeirismo e constatei, na mesma perspectiva consignada por Giumbelli (2003), a atualidade das relações simbólicas entre o poder médico e a figura simbólica das curandeirices praticadas por curandeiros nos seguintes termos. $O$ curandeirismo é um conceito de natureza controladora que tende a seguir caminhos de controle social pela corporação médica, que carece de distinções sociais para agir profissional e socialmente. Necessita, pois, de uma criação conceitual, complemento de sua imagem, como num espelho, visível somente por intermédio da utilização dos mecanismos de coerção presentes no código penal disponível por detrás da máquina estatal. Assim, coexistem no mundo social duas figuras que se completam: a dos que convivem cotidianamente com uma dupla faceta de médicos que curam doenças (salvam vidas) e a dos "curandeiros", que não curam doenças, põem em perigo vidas.

A fronteira simbólica que aqui interessa resgatar, entre o campo religioso e o campo médico, mais bem orientado pela sociologia de Bourdieu $(1998,1996)$, reconhece, de um ponto de vista das homologias e autonomia entre os campos, a importância e o alcance do conhecimento praxiológico: 
O conhecimento que podemos chamar de praxiológico tem como objeto não somente o sistema das relações objetivas que o modo de conhecimento objetivista constrói, mas também as relações dialéticas entre essas estruturas e as disposições estruturadas nas quais elas se atualizam e que tendem a reproduzi-las, isto é, o duplo processo de interiorização da exterioridade e de exteriorização da interioridade. (Bourdieu, 1983a, p.47)

Estou sugerindo pensar as disposições estruturadas no campo da saúde, predispostas a atualizar e reproduzir o processo de interiorização das práticas terapêuticas não-médicas e exteriorização da produção intelectual sobre elas, partindo do princípio em que se opera a interação entre o campo médico e religioso. A noção de saúde, portanto, atrela-se à noção de habitus da saúde, cuja estrutura estruturante, nos espaços relativamente autônomos da medicina e da religião, está mediada pelo curandeirismo, produto simbólico estratégico entre os demais bens de salvação.

\section{Considerações finais}

No presente artigo, procurei as razões discursivas sobre o risco do curandeirismo na sociedade, que representava, no passado, uma ação criminosa de perigo aos serviços médicos de saúde pública (Carvalho, 1999). Hoje, certamente, o curandeirismo não é uma ameaça à prática da saúde pública no Brasil, porém é preciso admitir a influência das relações simbólicas no habitus das pessoas (profissionais, pacientes e cuidadores) atuantes nos serviços de saúde.

Propus investigar a gênese do campo médico por um olhar sincrônico em relação ao campo religioso, por intermédio de um balanço bibliográfico sobre o tema estado de transe. Selecionei idéias, conceitos e teorias suscitadas por pessoas em certas posições sociais no campo intelectual brasileiro. Mostrei como o estado de transe - um problema social identificado na medicina do século XIX - transformou-se em discussão sociológica e antropológica sobre as práticas religiosas e terapêuticas nas ciências sociais.

Uma primeira conclusão refere-se ao aspecto negativo do curandeirismo dado pelo poder médico atuante no campo intelectual (Bourdieu, 1998). Trata-se de uma referência simbólica importante para a composição do campo da saúde. O equívoco epistemológico de Rodrigues, com base no animismo dos negros da Bahia (etiologia da doença mental na referência religiosa), permanece válido dentro de um contexto invertido onde o curandeiro figura no mundo social como representante das terapêuticas não-médicas em geral. Essa distorção atesta-se pela história da medicina brasileira, cuja retórica sobre o curandeirismo aparece argumentada contra o movimento hegemônico da medicina biomédica (Ibañez \& Marsiglia, 2000; Araújo, 1979; Santos Filho, 1977). A imagem do curandeiro permite expor sentido e entendimento ao poder médico em relação às curandeirices que, na atualidade, potencializam contradições lógicas e sintetizam a reprodução simbólica de todos os demais agentes não-médicos. Admitir a inexistência do curandeirismo e do curandeiro na sociedade seria reconhecer a hegemonia médica sobre as demais instâncias de saberes terapêuticos.

Desdobra-se, aqui, uma segunda conclusão. O significado negativo do curandeirismo (doença mental) é contraposto, anos depois, a aspectos positivos formulados pela sociologia da religião de Bastide e Camargo. É desse contexto que se pode afirmar que as terapêuticas não-médicas estiveram representadas positivamente no campo intelectual, condições criadas para se pensar a autonomia do campo religioso desvinculado do campo médico. O curandeirismo no campo religioso atua como produto simbólico de salvação na luta pela legítima distinção entre seitas e religiões oficiais (Montero, 2006; Giumbelli, 2000).

Do trabalho resulta, ainda, uma terceira conclusão que se volta para a área do conhecimento da Saúde Coletiva e que confirma o processo de autonomia relativa entre o campo médico e o campo religioso. Na práxis da Saúde Coletiva, quando surge a medicina homeopática como especialidade médica (Luz, 2005b; Laucas \& Luz, 1998), antes abordada sob o ângulo das práticas terapêuticas não-médicas (Barros \& Nunes, 2006; Barros, 2000), desenvolve-se um processo de reconhecimento social, embora em andamento, ou seja, não definido plenamente no campo intelectual, também 
porque os conhecimentos homeopáticos não são ensinados na maioria das escolas médicas brasileiras (Teixeira, 2006). Tal preconceito arraigado à cultura médica prova a influência do sentido negativo do curandeirismo, que vigora no habitus científico da saúde.

$\mathrm{Na}$ verdade, esse reconhecimento parcial na comunidade científica deve-se ao poder simbólico de associação da prática homeopática aos aspectos cognitivos do ideário da filosofia vitalista (Rosembaum, 2002), não necessariamente daquela combinação do animismo com o vitalismo do século XVIII nos primórdios da medicina científica (Abrantes, 1998; Darnton, 1988); antes, portanto, do surgimento da biomedicina científica (Camargo Jr., 2005). A homeopatia é reconhecida cientificamente quando se concebe o vitalismo não animista (Martins, 2004; Luz, 1988), que se distancia do campo religioso, deslocando-se do limiar jurídico do curandeirismo para efetivamente desenvolver-se como sistema médico na academia científica.

A hipótese inicial de que o curandeirismo transita como bem simbólico no campo da saúde ficou confirmada pela constatação das homologias e a autonomia relativa mantidas entre os campos médico e religioso. Historicamente, estão sustentadas as inter-relações do habitus gerado entre as posições sociais assumidas pelos agentes na prática médica e na prática religiosa, para os quais os diversos aspectos e significados do curandeirismo transitam por um campo simbólico de bens de saúde. O tema complementaridade, na Saúde Coletiva, exemplo do poder médico atuante no âmbito da prática social, inclui a problemática da ideologia das práticas terapêuticas não-médicas, que atualiza o debate em torno de um campo de forças da produção científica.

Afirmo que o campo da saúde guarda profunda relação com o habitus científico nessas circunstâncias, em que, na práxis das Ciências Sociais, da Medicina e da Saúde Coletiva, também transitam bens de salvação. Assim - retomando a pergunta colocada na introdução formulada em favor dos profissionais de saúde adeptos do espiritismo ante a crença da "medicina espírita" (Warren, 1986) -, as questões espirituais demarcam a cientificidade nas racionalidades médicas do campo da saúde na medida em que terapias espirituais não são caracterizadas por especialidades médicas e, portanto, não são definidas por práticas médicas ou práticas religiosas complementares.

Da dimensão categorial do habitus (Pinto, 2000) é que se criam as condições sociais de legitimidade e reconhecimento por meio de uma economia das trocas de bens simbólicos (Bourdieu, 1974). No habitus da saúde, a categoria espiritual - contraposta às concepções materialistas do corpo, e não da alma, embora não pertencente à racionalidade médica - representa um aspecto positivo na definição do conceito de saúde, na medida em que se distinguem, no plano discursivoideológico, os curandeiros atuantes com suas curandeirices na sociedade. O curandeirismo na Saúde Coletiva (Rabelo, 1994; Queiroz, 1991) representa, antes de tudo, um objeto de estudo sobre atuação no mercado simbólico de bens de salvação. Os curandeiros reproduzem e incorporam idéias e sentimentos da prática médica e religiosa (Loyola, 1984), mantendo-se a estrutura estruturada hegemônica da medicina na sociedade, e perfazendo os parâmetros estruturantes, nos termos empregados por Bourdieu, de uma relação dialética estabelecida entre as instituições médicas e religiosas.

Nesse contexto de atuação das ciências sociais em saúde, considerando-se, na práxis da Saúde Coletiva, os avanços e conflitos em destaque nas seguintes duas instâncias cognitivas - 1) a crescente tendência da perspectiva holística do processo saúde-doença-cuidado no modelo da complexidade e transdisciplinaridade (Almeida Filho, 2005; Czeresnia, 2003); e 2) na atual proposta de um modelo teórico para o campo da saúde dentro de uma cartografia conceitual da Saúde Coletiva (Almeida Filho, 2000) e o recente uso de diferentes significados de interpretação antropológica do conceito de doença (Almeida Filho \& Juca, 2002; Alves \& Minayo, 1994) - apresento a seguinte proposta de classificação, ainda que provisória e incipiente, dirigida à produção de conhecimentos, tendo em vista o curanderismo no habitus no campo da saúde brasileira, por intermédio da seguinte distinção crítica entre categorias de análise em relação ao campo social e religioso:

a) Religiosidade: referência a instituições e doutrinas religiosas, agentes religiosos atuantes em instituições, portanto, fora dos estabelecimentos de saúde que se utilizam práticas terapêuticas ou de curas voltadas aos adeptos. Pressupõe adesão a crenças e práticas relativas às igrejas, seitas ou instituições religiosas organizadas, mas também designa, no contexto das práticas de saúde, a 
religiosidade dos sujeitos (pacientes, profissionais de saúde e cuidadores), crença que professam no enfrentamento das doenças e da morte. Nesse sentido, a questão da fé religiosa pode estar aqui relacionada à experiência religiosa de pacientes [subjetividade aliada aos sofrimentos psicológicos] (Alves, Rabelo, Souza, 1999; Rabello, 1993). Por isso mesmo, nem sempre tomadas por evidências psicopatológicas (Moreira-Almeida, Lotufo Neto, Koenig, 2006), uma vez dadas as condições de possibilidades de identificar agentes religiosos com práticas do curandeirismo por via da psiquiatria (Dantas, Pavarin, Dalgalarrondo, 1999; Lotufo Neto, 1997). Também relacionado à cultura, o conceito de religiosidade popular representa uma fonte importante no habitus da saúde (Maués, 1994; Minayo, 1994; Brandão, 1988), fonte para os estudos de educação popular no campo da saúde (Valla, 2005; Vasconcelos, 1998).

b) Espiritualidade: termo ambíguo que designa: 1) ora referência às crenças dos sujeitos da saúde (agentes e pacientes), que atuam nas instituições de saúde ou fora delas; 2 ) ora determina a atuação da prática espiritual, que tem por base as crenças espiritualistas. Na primeira acepção, consideram-se as crenças pessoais dos sujeitos, não somente as crenças religiosas, mas também místicas, mágicas, extraordinárias ou idéias pelas quais militam e que representam um conjunto de convicções pertencentes ao habitus da saúde, dado pelas diferentes "cosmovisão de mundo". Incluem-se estudos de representações sociais (Alves \& Rabelo, 1998; Minayo, 1994; Queiroz, 1991). Na segunda acepção, tendo por base a crença na existência do espírito em oposição ao materialismo corporal, consideram-se as terapias espirituais (místicas, religiosas ou práticas espirituais) enquanto performances (Magnani, 1999) também voltadas para o enfrentamento da doença, e que podem resultar em melhoria das enfermidades corporais (Faria \& Seidel, 2006).

c) Assistência espiritual: termo que designa referência aos serviços prestados na prática de saúde multiprofissional (medicina, enfermagem, psicologia, assistência social, nutrição, fisioterapia). Por exemplo, a forma mais expressiva atualmente se encontra no cuidado a pacientes incuráveis ou portadores de doenças crônicas degenerativas. O trabalho designado na conceituação de cuidados paliativos (Menezes, 2004), direcionados aos limites da medicina curativa, representa o lugar de onde a assistência espiritual orienta-se por demandas críticas da bioética (Siqueira-Batista \& Schramm, 2004; Kovacs, 2003) suscitada no campo de atuação da prática médica institucional, na atualidade, um problema de saúde pública.

\section{Referências}

ABRANTES, P.C.C. Imagens de natureza, imagens de ciência. Campinas: Papirus, 1998.

ALMEIDA FILHO, N. Transdisciplinaridade e o paradigma pós-disciplinar na Saúde. Saúde Soc., v.14, n.3, p.30-50, 2005.

For a general theory of health: preliminary epistemological and anthropological notes. Cad. Saúde Pública, v.17, n.4, p.753-70, 2001.

O conceito de saúde e a vigilância sanitária: notas para a compreensão de um conjunto organizado de práticas de saúde. Brasília: Anvisa, 2000. Seminários permanentes.

ALMEIDA FILHO, N.; JUCA, V. Saúde como ausência de doença: crítica à teoria funcionalista de Christopher Boorse. Ciênc. Saúde Coletiva, v.7, n.4, p.879-89, 2002. 
ALVES, P.C.; MINAYO, M.C.S. (Orgs.). Saúde e doença: um olhar antropológico. Rio de Janeiro: Fiocruz, 1994.

ALVES, P.C.; RABELO, M.C. Repensando os estudos sobre representações e práticas em saúde/doença. In: (Orgs.). Antropologia da saúde: traçando identidade e explorando fronteiras. Rio de Janeiro: Editora Fiocruz/ Dumará, 1998. p.107-12.

ALVES, P.C.; RABELO, M. C.; SOUZA, I. M. Experiência da doença e narrativa. Rio de Janeiro: Fiocruz, 1999.

ANTUNES, J.L.F. Medicina, leis e moral: pensamento médico e comportamento no Brasil (1870-1930). São Paulo: Ed. Unesp, 1999.

ARAÚJO, A.M. Medicina rústica. 3.ed. São Paulo: Nacional, 1979.

ARAÚJO, M.A.M. Bactrins e quebra-pedras. Interface - Comunic., Saúde, Educ., v.4, n.7, p.103-10, 2000

AYRES, J. R. Cuidado e reconstrução das práticas de saúde. In: MINAYO, M.C.S.; COIMBRA JÚNIOR, C.E.A.(Orgs.). Críticas e atuantes: ciências sociais e humanas em saúde na América Latina. Rio de Janeiro: Editora Fiocruz, 2005. p.91-108.

BARROS, N.F. Medicina complementar: uma reflexão sobre o outro lado da prática médica. São Paulo: Anablume/Fapesp, 2000.

BARROS, N.F.; NUNES, E.D. Medicina alternativa e complementar no Brasil: um conceito e diferentes significados. Cad. Saúde Pública, v.22, n.10, p.2023-8, 2006.

BASTIDE, R. La transe. In: . Le rêve, la transe et folie. Paris: Flamarion, 1972. p.55-104.

Le spiritism au Brésil. Arch. Sociol. Religions, n.24, páginas, 1967.

As religiões africanas no Brasil: contribuição a uma sociologia da interpretação de civilizações. São Paulo: Pioneira, 1960.

BEZERRA DE MENEZES, A. Loucura sob novo prisma. Rio de Janeiro: FEB, 1987.

BOURDIEU, P. Campo do poder, campo intelectual e habitus de classe. In: MICELI, S. (Org.). A economia das trocas simbólicas. 5.ed. São Paulo: Perspectiva; 1998. p.183-202.

Razões práticas: sobre a teoria da ação. São Paulo: Papirus, 1996.

Esboço de uma teoria da prática. In: ORTIZ, R. (Org.). Pierre Bourdieu: sociologia. São Paulo: Ática, 1983a. p.46-81.

O campo científico. In: ORTIZ, R. (Org.). Pierre Bourdieu: sociologia. São Paulo: Ática, 1983b. p.122-55.

A economia das trocas simbólicas. São Paulo: Perspectiva, 1974.

BRANDÃO, C.R. Crença e identidade: campo religioso e mudança cultural. Trabalhos Antropol., n.3, p.7-75, 1988. 1980.

Os deuses do povo: um estudo sobre a religião popular. São Paulo: Brasiliense,

BUSS, P.M. Uma introdução ao conceito de promoção de saúde. In: CZERESNIA, D.

(Org.). Promoção da saúde: conceitos, reflexões e tendências. Rio de Janeiro: Fiocruz, 2003. p.15-38.

CAMARGO, C.P. Católicos, protestantes e espíritas. Petrópolis: Vozes, 1973. 
CAMARGO, C.P. Kardecismo e umbanda: uma interpretação sociológica. São Paulo: Pioneira, 1961.

CAMARGO JR., K.R. The biomedicine. Physis, v.15, supl., p.177-201, 2005. Disponível em: <http://www.scielo.br/scielo.php?script=sci_arttext\&pid=S0103-

73312005000300009\&lng=pt\&nrm=iso > .Acesso em: 01 out. 2007.

CARVALHO, A.C.D. Curandeirismo e medicina: práticas populares e políticas estatais de saúde em São Paulo nas décadas de 1930 e 1940. Londrina: Ed. UEL, 1999.

CAVALCANTI, M.L.V.C. O mundo invisível: cosmologia, sistema ritual e noção de pessoa no Espiritismo. Rio de Janeiro: Zahar, 1983.

CHALHOUB, S. et al. Artes e ofícios de curar no Brasil: capítulos de história social. Campinas: Ed. Unicamp, 2003.

COELHO, M.T.A.D.; ALMEIDA FILHO, N. Conceitos de saúde em discursos contemporâneos de referência científica. Hist. Cienc. Saúde - Manguinhos, v.9, n.2, p.315-33, 2002.

CONCONE, M.H.V.B. Umbanda: uma religião brasileira. São Paulo: FFLCH/USP/CER, 1983.

CORRÊA, M. As ilusões da liberdade: a escola Nina Rodrigues e a antropologia no Brasil. 2.ed. Bragança Paulista: Editora da Universidade São Francisco, 2000.

COSTA, J.F. História da psiquiatria no Brasil: um corte ideológico. 4.ed. Rio de Janeiro: Xenon, 1989.

CUETO, M. The origins of primary health care and selective primary health care. Am. J. Public Health, n.94, p.1864-74, 2004.

CZERESNIA, D. O conceito de saúde e a diferença entre prevenção e promoção. In: CZERESNIA, D.; FREITAS, C. M. (Orgs.). Promoção da saúde: conceitos, reflexões, tendências. Rio de Janeiro: Editora Fiocruz, 2003. p.39-53.

DANTAS, B.G. Vovó nagô e papai branco: usos e abusos da África no Brasil. Rio de Janeiro: Graal, 1988.

Repensando a pureza nagô. Relig. Soc., v.25, n.3, p.15-20, 1982.

DANTAS, C.R.; PAVARIN, L.B.; DALGALARRONDO, P. Sintomas de conteúdo religioso em pacientes psiquiátricos. Rev. Bras. Psiquiatr., v.21, n.3, p.158-64, 1999.

DARNTON, R. O lado oculto da revolução: Mesmer e o final do lluminismo na França. São Paulo: Cia. das Letras, 1988.

FARIA, J. B.; SEIDL, E. M. F. Religiosity, coping and well-being in people living with HIV/ Aids. Psicol. Estud., v.11, n.1, p.155-64, 2006.

FERNANDES, R.C. Religiões populares: uma visão parcial da literatura recente. BIB - Bol. Inform. Bibliogr. Ciênc. Soc., n.18, p.3-26, 1984.

FERRETTI, S.F. Notas sobre o sincretismo religioso no Brasil - modelos, limitações, possibilidade. Rev.Tempo, n.11, p.13-26, 2001.

Revisão da literatura sobre sincretismo religioso afro-brasileiro. In:

Repensando o sincretismo: estudo sobre a Casa de Minas. São Paulo: Edusp/Fapema, 1975. p.41-75.

FRY, P. Prefácio. In: DANTAS, B.G. Vovô nagô e papai branco: usos e abusos da África no Brasil. Rio de Janeiro: Graal, 1988. p.13-17. 
GIUMBELLI, E. O 'baixo espiritismo' e a história dos cultos mediúnicos. Horiz. Antropol., v.9, n.19, p.247-81, 2003.

O fim da religião: controvérsias acerca das "seitas" e da "liberdade religiosa" no Brasil e na França. 2000. Tese (Doutorado) - Programa de Pós-Graduação em Antropologia Social, Universidade Federal do Rio de Janeiro, Rio de Janeiro. 2000.

O cuidado dos mortos: uma história da condenação e legitimação do Espiritismo. Rio de Janeiro: Arquivo Nacional, 1997a.

Heresia, doença, crime ou religião: o espiritismo no discurso de médicos e cientistas sociais. Rev. Antropol., v.40, n.42, p.31-82, 1997b.

Em nome da caridade: assistência social e religião nas Instituições Espíritas. Rio de Janeiro: Instituto de Estudos da Religião (ISER), 1995.

GUEDES, J.S.; BARATA, L.R.B.; CORRÊA, M.C.M.M.A. Os hospitais filantrópicos e beneficentes e sua inserção nos Sistemas Unificados e Descentralizados de Saúde SUDS no Brasil. Brasília: OPS, 1988.

HESS, D.J. Disobsessing disobsession: religion, ritual, and the social sciences in Brazil. Cult. Anthropol., v.4, n.2, p.182-93, 1989.

HESS, D.J. Spirits and scientists: ideology, spiritism and Brazilian culture. Pennsylvania: The Pennsylvania State University Press, 1991.

IBAÑEZ, N.; MARSIGLIA, R. Medicina e saúde: um enfoque histórico. In: CANESQUI, A.M. (Org.). Ciências Sociais e Saúde para o ensino médico. São Paulo: Hucitec/Fapesp, 2000. p. 49-74.

KOVACS, M.J. Bioethics concerning life and death. Psicol. USP, v.14, n.2, p.115-67, 2003.

LANDIM, L. Para além do mercado e do estado? Filantropia e cidadania no Brasil. Rio de Janeiro: Instituto de Estudos da Religião (ISER), 1993.

LAPLANTINE, F.; RABEYRON, P.L. Medicinas paralelas. São Paulo: Brasiliense, 1989.

LAUCAS, C.R.; LUZ, M. A estrutura do campo médico homeopático do Rio de Janeiro reflexões sobre a produção do conhecimento como elemento básico de estruturação institucional sistêmica do campo. Estud. Saúde Coletiva, n.178, p.3-29, 1998.

LEWGOY, B. Os espíritas e as letras: um estudo antropológico sobre a cultura escrita e a oralidade no espiritismo kardecista. 2000. Tese (Doutorado) - Programa de PósGraduação em Antropologia Social, Faculdade de Filosofia, Letras e Ciências Humanas, Universidade de São Paulo, São Paulo. 2000.

LOTUFO NETO, F. Psiquiatria e religião: a prevalência de transtornos mentais entre ministros religiosos. 1997. Tese (Livre Docência) - Departamento de Psiquiatria, Faculdade de Medicina, Universidade de São Paulo, São Paulo. 1997.

LOYOLA, M.A. Médicos e curandeiros: conflito social e saúde. São Paulo: Difel, 1984.

LUZ, M. Contemporary culture and complementary medicine: new paradigm in health in the end of the century. Physis, v.15, supl, p.145-76, 2005a.

Novas práticas em Saúde Coletiva. In: MINAYO, M.C.S.; COIMBRA JÚNIOR, C.E.A.(Orgs.). Críticas e atuantes: ciências sociais e humanas em saúde na América Latina. Rio de Janeiro: Editora Fiocruz, 2005b. p.33-46. IMS, 1993

Racionalidades médicas e terapêuticas alternativas. Rio de Janeiro: UERJ/ 
LUZ, M. Natureza e razão no tempo e no espaço mecânicos. In: Natural, racional, social: razão médica e racionalidade científica moderna. São Paulo: Editora Campus, 1988. p.42-55.

MACHADO, R. et al. Danação da norma: medicina social e constituição da psiquiatria no Brasil. Rio de Janeiro: Graal, 1978.

MAGGIE, Y. Medo do feitiço: relações entre magia e poder no Brasil. Rio de janeiro: Arquivo Nacional, 1992.

Cultos afro-brasileiros: consenso e diversidade. In: LANDIM, L. (Org.). Sinais dos tempos: igrejas e seitas no Brasil. Rio de Janeiro: Instituto de Estudos da Religião, 1989. p.77-82.

O medo do feitiço: verdades e mentiras sobre a repressão às religiões mediúnicas. Relig. Soc., v.13, n.1, p.72-86, 1986.

MAGNANI, J.G.C. Mystica urbe: um estudo antropológico sobre o circuito neoesotérico na metrópole. São Paulo: Studio Nobel, 1999.

MAIO, M.C. A medicina de Nina Rodrigues: análise de uma trajetória científica. Cad. Saúde Pública, v.11, n.2, p.226-37, 1995.

MAIO, M.C.; SANTOS, R.V. Política de cotas raciais, os "olhos da sociedade" e os usos da antropologia: o caso do vestibular da Universidade de Brasília (UnB). Horiz.

Antropol., v.11, n.23, p.181-214, 2005.

MARTINS, A. Philosophy and health: genealogical and philosophical-conceptual methods. Cad. Saúde Pública, v.20, n.4, p.950-8, 2004.

MAUÉS, R.H. Medicinas populares e "pajelança cabocla" na Amazônia. In: ALVES, P.C.; MINAYO, M.C.S. (Orgs.). Saúde e doença: um olhar antropológico. Rio de Janeiro: Fiocruz, 1994. p.73-82.

MENEZES, R.A. Em busca da boa morte: antropologia dos cuidados paliativos. Rio de Janeiro: Garamond/ Fiocruz, 2004. v.1.

MESTRINGER, M.L. Estado entre a filantropia e a assistência social. São Paulo: Cortez, 2001.

MINAYO, M.C.S. Representações da cura no catolicismo popular. In: ALVES, P.C.; MINAYO, M.C.S. (Orgs.). Saúde e doença: um olhar antropológico. Rio de Janeiro: Fiocruz, 1994. p.57-71.

MONTERO, P. Religião, pluralismo e esfera pública no Brasil. Novos Estud. - CEBRAP, n.74, p.47-65, 2006. Disponível em: <http://www.scielo.br/scielo.php?script=sci_arttext $\&$ pid $=$ S0101-33002006000100004\&lng=pt\&nrm=iso >. Acesso em: 05 out. 2007.

Magia e pensamento mágico. 2.ed. São Paulo: Ática, 1990.

. Da doença à desordem: a magia na umbanda, Rio de Janeiro: Graal, 1985.

MOREIRA-ALMEIDA, A.; LOTUFO NETO, F.; KOENIG, H.G. Religiosidade e saúde mental: uma revisão. Rev. Bras. Psiquiatr., v.28, n.3, p.242-50, 2006.

NEGRÃO, L.N. Entre a cruz e a encruzilhada: formação do campo umbandista em São Paulo. São Paulo: Edusp, 1996.

NEVES. D.P. As “curas milagrosas" e a idealização da ordem social. Niterói: UFF, 1984.

NEVES, D.P.; SEIBLITZ, Z. Saúde e doença: merecimento e castigo. Médico Moderno, V.3, n.7, p.57-74, 1984. 
ODA, A.M.G.R. Alienação mental e raça: a psicopatologia comparada dos negros e mestiços brasileiros na obra de Raimundo Nina Rodrigues. 2003. Tese (Doutorado) Faculdade de Ciências Médicas, Universidade Estadual de Campinas, Campinas. 2003.

ORTIZ, R. A morte branca do feiticeiro negro: umbanda, integração de uma religião numa sociedade de classes. Petrópolis: Vozes, 1978.

PEIXOTO, I. D. Superstição e crime no Brasil. São Paulo: Revista dos Tribunais, 1980.

PINTO, L. Pierre Bourdieu e a teoria do mundo social. Rio de Janeiro: FGV, 2000.

PORTELA, M.C. et al. Characterization of assistance among philanthropic hospitals in Brazil. Rev. Saúde Pública, v.38, n.6, p.811-8, 2004. Disponível em: <http://www. scielo.br/scielo.php?script $=$ sci_arttext $\&$ pid $=$ S0034-89102004000600009\&Ing $=$ pt\&nrm $=$ iso $>$. Acesso em: 01 out. 2007

PUTTINI, R.F. O poder médico e sua relação com outras práticas de cura. Campinas: Departamento de Medicina Preventiva e Social, Unicamp, 1989. (Relatório de Pesquisa)

QUEIROZ, M.S. Representações sobre saúde e doença: agentes de cura e pacientes no contexto do SUDS. Campinas: Editora da Unicamp, 1991.

RABELO, M.C. Religião, ritual e cura. In: ALVES, P.C.; MINAYO, M.C.S. (Orgs.). Saúde e doença: um olhar antropológico. Rio de Janeiro: Fiocruz, 1994. p.47-56.

REBOLLO, R.A. Exame de bases cientificas e metafísicas da homeopatia de Samuel Hahnemann. 1993. Tese (Doutorado) - Faculdade de Filosofia, Letras e Ciências Humanas, Universidade de São Paulo, São Paulo. 1993.

RIVERO, D.A.T. Alma-Ata: 25 años después. Rev. Perspec. Salud, v.8, n.2, p.2-7, 2003.

RIZZI, N.D. Visões do transe religioso. 1995. Dissertação (Mestrado) - Programa de Pós-Graduação em Sociologia, Faculdade de Filosofia, Letras e Ciências Humanas, Universidade de São Paulo, São Paulo. 1995.

RODRIGUES, R.N. O animismo fetichista dos negros baianos. Rio de Janeiro: Civilização Brasileira, 1935.

ROSENBAUM, P. Homeopatia: medicina interativa, história lógica da arte de cuidar. Rio de Janeiro: Imago, 2002.

A homeopatia como medicina do sujeito: raízes históricas e fronteiras epistemológicas. 1999. Dissertação (Mestrado) - Faculdade de Medicina, Departamento de Medicina Preventiva, Universidade de São Paulo, São Paulo. 1999.

SAMAJA, J. Fundamentos epistemológicos de las ciências de la salud. 1997. Tese (Doutorado) - Escola Nacional de Saúde Pública, Fundação Oswaldo Cruz, Rio de Janeiro. 1997.

SANTOS FILHO, L. História geral da medicina brasileira. São Paulo: Hucitec/Edusp, 1977.

SCHRITZMEYER, A.L.P. Sortilégio de saberes: curandeiros e juízes nos tribunais brasileiros (1900-1990). São Paulo: IBCCRIM, 2004.

SCHWARCZ, L.K.M. O espetáculo das raças: cientistas, instituições e pensamento racial no Brasil, 1870-1930. São Paulo: Cia. das Letras, 1993.

SEGRE, M.; FERRAZ, F.C. O conceito de saúde. Rev. Saúde Pública, v.31, n.5, p.538-42, 1997. 
SEIBLITZ, Z.M.L. Dentro de um ponto riscado: estudo de um centro espírita na zona norte do Rio de Janeiro. 1979. Dissertação (Mestrado) - Programa de Pós-Graduação em Antropologia Social, Universidade Federal do Rio de Janeiro, Rio de Janeiro. 1979.

SERAPIONI, M. The role of family and primary network in the reform of social policies. Ciênc. Saúde Coletiva, v.10, supl., p.243-53, 2005.

SIQUEIRA-BATISTA, R.; SCHRAMM, F.R. Eutanásia: pelas veredas da morte e da autonomia. Ciênc. Saúde Coletiva, v.9, n.1, p.31-41, 2004.

STEPAN, N.L. A hora da eugenia: raça, gênero e nação na América Latina. Rio de Janeiro: Fiocruz, 2005.

STOLL, S.J. Religião, ciência ou auto-ajuda? Trajetos do Espiritismo no Brasil. Rev. Antropol., v.45, n.2, p.361-402, 2002.

. Entre dois mundos: o Espiritismo da França e no Brasil. 1999. Tese (Doutorado) - Programa de Pós-Graduação em Antropologia Social, Faculdade de Filosofia, Letras e Ciências Humanas, Universidade de São Paulo, São Paulo. 1999.

TEIXEIRA, M.Z. Homeopatia: ciência, filosofia e arte de curar. Rev. Med., v.85, n.2, p.30-43, 2006.

VALLA, V.V. Classes populares, apoio social e emoção: propondo um debate sobre religião e saúde no Brasil. In: MINAYO, M.C.S.; COIMBRA JÚNIOR, C.E.A. (Orgs.).

Críticas e atuantes: ciências sociais e humanas em saúde na América Latina. Rio de Janeiro: Fiocruz, 2005. p.77-89.

VASCONCELOS, E.M. Educação popular como instrumento de reorientação das estratégias de controle das doenças infecciosas e parasitárias. Cad. Saúde Pública, v.14, supl.2, p.39-57, 1998.

VELHO, Y.M.A. A guerra de Orixá: um estudo de ritual e conflito. Rio de Janeiro: Zahar, 1975.

WARREN, D. A medicina espiritualizada: a homeopatia no Brasil do século XX. Relig. Soc., v.13, n.1, p.88-107, 1986.

A terapia espírita no Rio de Janeiro por volta de 1900. Relig. Soc., v.13, n.1, p.56-83, 1984.

WHO. Constituição da Organização Mundial de Saúde. Conferência Internacional da Saúde. New York: WHO, 1948. Disponível em: <http://www.who.int/governance/eb/ who_constitution_sp.pdf>. Acesso em: 01 jan. 2008.

WHO/UNICEF. World Health Organization/United Nations Children's Fund. Primary health care: report of the International Conference on PHC, Alma-Ata, USSR, 6-12, sept. 1978. Geneve: WHO, 1978. Disponível em: <http://www.who.int/hpr/NPH/ docs/declaration_almaata.pdf>. Acesso em: 01 jan. 2008.

WHO. World Health Organization/Europe. Health promotion: a discussion document on the concepts and principles. Copenhagen: WHO/Regional Office for Europe, 1984. 
PUTTINI, R.F. Curanderismo y el campo de la salud en Brasil. Interface - Comunic., Saúde, Educ., v.12, n.24, p.87-106, jan./mar. 2008.

El objetivo general del presente artículo es el de colaborar para la discusión sobre el campo de la salud. Específicamente pretende contribuir para la reflexión del poder médico hegemónico y sus relaciones con las prácticas relacionadas al curanderismo. Considerando la teoría del campo y del habitus de Pierre Bourdieu, se discute sobre el curanderismo con base en una revisión del concepto de trance en el campo intelectual como objeto del habitus científico formado entre la práctica médica y la práctica religiosa. Finalmente, por medio de temas contemporáneos compartidos por las Ciencias Sociales y por la Salud Colectiva, se indica cómo el curanderismo - aspecto negativo para el campo médico - se transforma en aspecto positivo en el campo de la Salud Colectiva.

Palabras clave: Religión y medicina. Salud. Espiritualidad. Terapias espirituales.

Recebido em 22/02/06. Aprovado em 03/10/07. 